\title{
Advertisement Analysis: A Comparative Critical Study
}

\author{
Noureldin Mohamed Abdelaal \\ Faculty of Modern Languages and Communication \\ Universiti Putra Malaysia \\ E-mail: nourabdelal@yahoo.com \\ Amal Saleh Sase \\ Faculty of Modern Languages and Communication \\ Universiti Putra Malaysia \\ E-mail: saseamal@yahoo.com
}

Doi:10.7575/aiac.alls.v.5n.6p.254

Received: 10/09/2014

URL: http://dx.doi.org/10.7575/aiac.alls.v.5n.6p.254

Accepted: 04/11/2014

\begin{abstract}
This study aimed at analyzing two advertisements, and investigating how advertisers use discourse and semiotics to make people and customers buy into their ideas, beliefs, or simply their products. The two advertisements analyzed are beauty products which have been selected from internet magazines. The methodology adopted in this study is qualitative method. The first advertisement is analyzed qualitatively in terms of content; there was no focus on a specific theoretical frame work, while the second advertisement analysis is based on Fairclough's framework, the critical discourse analysis framework.
\end{abstract}

Keywords: critical discourse, analysis, Fairclough's, advertisements; content

\section{Introduction}

Advertising is mass media content intended to persuade audiences, readers, viewers or listeners to take action on products, services and ideas. The idea is to drive consumer behavior in a particular way in regard to a product, service or concept. Yet, some other scholars disagree, Cook (1992) states that advertisements can amuse, inform, misinform, worry or warn.

Advertisements can be used to refer to text, audio, video, photography and graphic designs. Advertising can be channeled through many tubes like newspapers, magazines, radio and television broadcasts, stage shows, websites, billboards, posters, wall paintings, cars,... etc. As a matter of fact, advertisers usually have full control of the message all the way to the audience. However, for an advertisement to be effective, it should have smart placement where it will be seen by your target audience; a persuasive headline, which is the most important technical aspect of your advertisement; a powerful headline which suggests benefits or news. Readers scan headlines, so if yours does not grab attention, it will not be read. Eye-catching graphics are also important means of getting your audience to read your advertisement. An attractive graphic and a strong headline will pull a reader or viewer into your advertisement. Focusing on the objective is required to persuade consumers to fulfill your one main objective. Having multiple objectives will confuse people and then they will not get the message. Tempting offer including valuable bonuses and risk-free, easy-pay terms, and low price will help in promoting the product; it will help purchasers reconcile your offer in their minds, so it should make sense and be believable.

\subsection{Objectives}

This study aims at:

\section{Analyzing two advertisements in terms of content}

2. Looking deeply into the language employed in the discourse of advertisement, the verbal sign and the nonverbal sign, that is, to identify the purpose, message and implication of power behind the advertisement.

\section{Literature review}

\subsection{Background}

In today's society, advertisement plays an important role in communicating messages; it is an inherent part of our daily life. Among others, advertising contributes to the creation of opinions, the production of certain roles that viewers take up after their idols and the creation of shared knowledge. Advertisement is not only an economic entity, but it also deals with values, attitudes and ideas shaping culture (Sinclair 1987). Advertising is a social practice which does not work in vacuum; it interlinks many things together like person and object, symbol, symbolism and power, and communication and satisfaction (Jhally, 1987). To be truthful, we cannot separate the content of an advertisement from culture. 


\subsection{Gender and beauty in Advertisements}

A study which was carried out by Orth and Holancova (2004) found that customers responded most favorably to exclusive portrayals of members of their in-group, and that women response is not effective when men are shown as superior in the advertisement. However advertisements usually portray women as sexual objects who can play the role of sexually attractive targets; they cannot make decisions or play important roles (Kang, 1997). Kang (ibid) states that women alone or men alone are mostly used in advertisements, but women are used in cosmetics as independent and powerful; women are represented in demeaning roles. They might play a role in convincing us to buy a product. In other words, women sexuality and nudity sometimes are deployed in advertisements due to the increasing culture of being exposed to pornography; advertisers believe that sexual appeal increases the selling rate of their products. Even in nonwoman related articles we still see women as a sexual appeal for selling these products though it is not always like that because women sexuality can positively affect the selling rate of a product if only the product is cheap (Tuzla, 2012).

Beauty is one of the main focuses of media in general and in advertising in particular. Female beauty is expressed in media with youthful attributes, including wide eyes, full lips, high cheekbones and flawless skin (Pamela and Nicholas, 2013).

\subsection{Semiotics in Advertisements}

Photographs, used in print advertisements, work as a system of signs that gives form and meaning to consciousness and reality. There are always two modes of communication in a printed advertisement; a verbal mode and a visual one, and which interact together. These two modes can be expressed through the different signs utilized like colors, typed words, and photographs. The more these signs used effectively, the more they can convince the customer to buy the product. Semiotic reference plays an important role in the relationship between discourse and ideology (Najafian and Dabaghi, 1991).

\subsection{Critical discourse analysis (CDA) in Advertisements}

Fairclough (1989) defines CDA as a kind of social practice where power and ideology influence and interact with one another. Dijk (1995) also defines critical discourse analysis as a type of analytical discourse research that discusses social power abuse, dominance and inequality, and how they are reproduced, enacted and resisted. Beauty as an ideology is produced and reproduced through advertisements. Beauty products advertisements usually manipulate people to an extent that they believe whatever said is true (Kaur et al., 2013).

\section{Methodology and Theoretical Framework}

\subsection{Research design}

A qualitative design was adopted for this study. A qualitative study was appropriate in this study which seeks to investigate how discourse in advertisements involves people's construction of meanings. The first advertisement was analyzed in terms of content; it did not focus on a specific theoretical frame work, while the second advertisement analysis is based on Fairclough's framework, the CDA framework.

\section{2 sampling}

Two advertisements have been selected from beauty magazine. The first advertisement is Olay Anti-ageing Beauty Product, while the second one is Beauty Product: Dove lotion firming

\subsection{Data analysis}

Content analysis has been adopted for the first advertisement, while Fairclough's framework, the CDA framework was adopted for the second one.

\section{Analysis of advertisements}

\section{Content analysis of the target Advertisements}

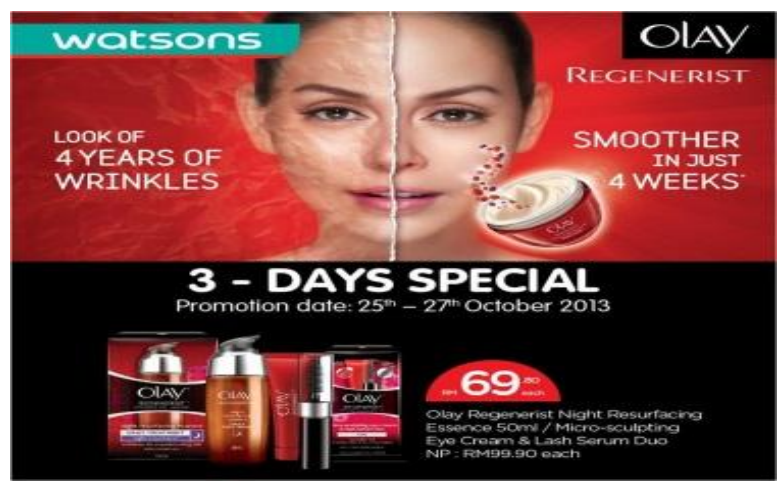




\section{Advertisement 1}

\section{Olay Anti-ageing Beauty Product}

\subsection{Thesis of the advertisement}

The advertisement is a beauty product; it mainly promotes a type of cream. It is one of Olay company beauty products. The thesis of the product is: buy our product to look younger and more beautiful in few weeks; it is represented by a woman whose face split into two parts; one part with wrinkles and the other one without wrinkles. The background of the advertisement is red. Not many words used in the advertisement, and the words are written in white. It is presented by a very beautiful woman whom each counterpart hopes to look like because she is so beautiful, but pay attention she did not use to be that beautiful. She was old with wrinkles as it is displayed on the first right half of the picture, but after just four weeks she became young and extremely beautiful. The advertisement displays the picture of the woman in two halves; the right half with wrinkles represents the woman before using the cream, while the left half which is not only without wrinkles but with smooth skin.

\subsection{Audience}

This advertisement triggers feelings and emotions of old women and make them fly over with their dreams; it is that simple; use this cream not only to get rid of wrinkles but to be also gorgeous and beautiful woman with smooth skin. Fantasy, imagination and dreams are given free wings to fly. Myth is employed here because all that does not apply to truths or facts. This advertisement targets old women who face wrinkles due to ageing. Old women who lost their beauty and wrinkles came up to cover their faces are dreaming of getting rid of such wrinkles. They are liable to believe whatever been told to them; they are eager to look beautiful and younger, and with smooth skin.

The age group which is targeted by this advertisement ranges from $40 \mathrm{~s}$ to $60 \mathrm{~s}$ or above. Wrinkles are likely to appear on the face of a woman at the age of forty, and sometimes before. At this age women feel desperate and they start fighting to search for something which makes them look younger and more beautiful. They have wild dreams and history which is full with pictures when they were young and beautiful. Now, when they look back they hope they can get younger again and beautiful. This advertisement says to old or growing-old women: we have the myth solution for your concern; if you have horrible wrinkles like the ones you see on the right part of the picture, just use this product for four weeks to see a beyond imagination result. You, my dear customer, will look like this beautiful woman in a short time. Do not hesitate; come to buy it; especially when it is on promotion like now.

\subsection{Myth in the advertisement}

Myth in the advertisement was deployed through use of signs and colors. Myth is commonly used to refer to beliefs which are demonstrably false, but according to semiotics, myths can be seen as extended metaphors. The power of such myths is that they 'go without saying' and so appear not to need to be deciphered, interpreted or demystified (Chandler, 2000). In this advertisement we can easily identify how myth is employed; it attempts to tell interested women who are old with wrinkles, wrinkles which have accumulated for four years, that just in four weeks these wrinkles will disappear. Targeted women will not think deeply about it because they are inclined to believe it; they will just look at the left side of the picture to see a face smooth with no wrinkles; a shining face which each woman, let alone old women, dreams of. Thus, the advertisement tries to convince women to take it for granted that their wrinkles and ageing troubles will be resolved once they use this cream. The cream will not efface the wrinkles from the face but from every part of the body; it will make you younger. This advertisement targets dreamy women well; women by nature do not like to grow old or to look old; they dream of looking young forever. This advertisement says to its target audience I have the solution; you will no more look old.

The color red is one thought to be the color which enflames emotions and feelings. It is a symbol of high energy. Red and its many shades of color are also used as a symbol of heart and love. Red has been found to have such a huge impact on people; it can even cause the heart to beat faster. It is an extremely powerful color. It is the bang that hits your eyes, and as a result, it symbolizes energy, power, vitality and vigor. Red is an attractive color to nearly everyone, and it can be used for anything exciting and able. Sometimes the power of products is described by the use of red. Red color is used in this advertisement to invoke targeted women as it iss the only color that can really portray any vigorous reaction. It gives a message to old women that if they used this cream, they would not only be without wrinkles or with smooth skin but they will also be more vigorous, energetic, active, attractive, and sexy. In fact it is the use of myth thru colors. Thus, overall, red is a pretty useful advertising color, especially for beauty products. Here, it might also give sexual hint; in other words, women who use this product will look sexy and attractive for men. Besides; the red color has a great effect on a customer. It can convince him to buy the product. (Gonzalez, 2005)

The white color is used to write the letters to reflect safety and simplicity. The advertisement conveys a message by using white color in writing letters to show that this product is safe and simple. Colors are an integral part of our daily life. They are used in a special way in advertisements to attract customers; they convey deep meaning. Right colors please the eyes and send positive messages.

\subsection{Positioning}

The woman of the advertisement is centered in the picture to get the attention. She is smiling with a shiny face telling the other women that you can be as young and beautiful as I am; just hurry and buy the cream. Dividing the face of the advertisement women to two sides, one before using the cream and another side after using the cream fits well because it will make the target audience hold comparisons. Another thing is that the side with wrinkles is shown with horrible 
wrinkles to affect women because women can seldom be with such type of wrinkles, and in spite of that her face became smooth and beautiful in just four weeks.

\subsection{Semiotics in the advertisement}

The picture of the advertisement woman represents the iconic sign. The picture is the signified; the picture of a woman who used to look ugly with wrinkles before the use of the cream, but she shifted to be charming beautiful woman with smooth skin and with no wrinkles after only four weeks of the use of cream. Here, we have a denotative meaning of the sign and a connotative one. The denotative meaning for the picture is a woman who looked charming after using the cream, while the connotative meaning includes more than that; it refers to beauty, charm, vigor, the powerful effect of the cream, and the dreamy world with no fear of ageing or wrinkles. So the connotative meaning expresses the myth used in the advertisement, since all these things are unrealistic and cannot be true.

Another type of signs used in the advertisement is the index sign which is implied in the use of colors. The color red in the advertisement refers to vigor, beauty and attraction because it is the romantic color which arouses the emotions and feeling of men. So the advertisement says that using this cream will make you attractive and sexy.

\subsection{Lexical features in the advertisement}

This advertisement uses simple words with simple structure so as to make it easy to read and grasp the intended message. The use of the noun "look" to connote how a face with wrinkles will convey bad look, in comparison to another shiny look after using the cream. The use of the adjective "smoother" in the comparative form conveys the great prospected result from using the cream. Using the number " 4 " once to refer to years, and another time to refer to weeks, is to get the attention of a customer easily, and so as not to make her exert great effort to remember the concept. "4" is also written in numbers not letters to make it easily read and memorable. Phrases instead of complete sentences are used to convey the message because long sentences do not attract customers and make them feel bored soon. Short phrases and sentences are easily read and memorable.

\subsection{Syntactic features in the advertisement}

\subsubsection{Use of simple sentences}

To convey meaning clearly and simply, simple phrases are used to avoid vagueness or obscurity. The phrases used are: 'look of 4 years of wrinkles'; 'smoother in just 4 weeks'. Although they are phrases, they convey the meaning well, in a simple way.

\subsubsection{Use of minor sentences}

Using of minor sentences does not make the reader take time to read the advertisement; henceforth, he does not feel bored soon. It also leaves space for focusing on the picture.

\subsubsection{Use of parallelism}

The advertisement uses parallelism to add clarity, rhythm, and balance to the phrases uses. Look at the use of the number " 4 " and how it is repeated in the two phrases

\section{Advertisement 2}

\section{Beauty Product: Dove lotion firming}

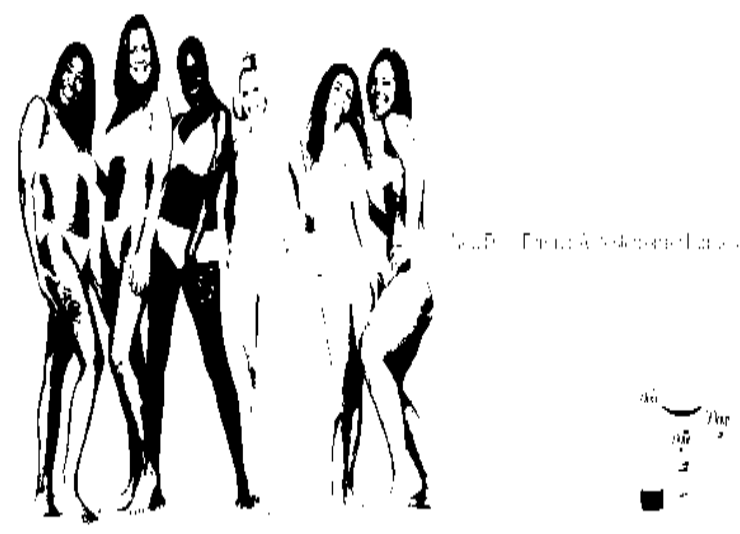

This picture is taken from Dove webiste.

The producer of this advertisement is Dove and its objective is to introduce its new product. The advertisements introduces a new product (beauty discourse) and six women in the picture which implies that it is related to gender discourse. Dove's lotion firming advertisement has six diverse women posing together in a very confident way. These women are posing in their undergarments making it seem like they have a high self-esteem about their natural womanly curves. All these women seem to have been selected from those in an everyday society instead of celebrities.

This Dove advertisement strictly targets its viewers' emotional appeal in several ways. First: there is no a distracting background color or objects in the advertisement so that the viewers can focus solely on the appearance of the women. These six average looking women from different sizes, shapes, colors and ethnics, and who are smiling in confidence to 
make the advertisement's goal clear. Every one of them is shown with a bright and confident smile while comfortably posing in their own skin. With these women showing self-confidence, happy and joy, it influences the viewers who want to feel this way. The viewers want to feel as if they can be accepted into a group of such confident women. With these women, just wearing undergarments, they remain satisfied with their body image and sexuality. This reflects to the viewers that there is no fear to show their real physical appearances, and makes the viewer feel sexy in their own body as well. The orientation of the advertisement is also set up in a front view perspective to put an emphasis on the body image and facial expressions of each of the women. In order to draw focus on the women, each of them is looking directly at the camera so they can imply a sense of power to their audience. The advertisement includes women who come from all different ethnicities in life so that the viewer can see that beauty is universal and comes in all different forms. Although the advertisement focuses on the element of universal beauty, they fail to put their focus on inner beauty and seem to focus just on the outer beauty. Moreover, the use of little clothing implies sexiness and can leave the viewers wishing they could also feel that way in little clothing. Many of the elements in this advertisement will have a strong emotional appeal to their audience.

The only thing that Dove has included in the advertisement is their logo, their slogan, "New Dove Firming. As tested on real curves" and a picture of the lotion line that they sell. The color white is used to symbolize that with Dove you can look forward to a brighter future. The image is also taken from a long distance in order to show the whole body image of the individuals and their natural curves. This leaves the audience room to think that their curves could be altered to be beautiful if they were to try Dove's lotion products.

Since today's media advertisements are heavily focused on supermodel-like qualities, it targets females and makes them feel as if that's how they need to look. However, for this advertisement Dove used the average woman diminishing this feeling of their viewers. This demonstrates the use of pathos by Dove's advertisement. With this advertisement, Dove tries to send the message that not all women have to have impeccable bodies and that the physical features they attain are beautiful. I think that Dove wants women to know that they make products for all types of women and it can help to restore and attain their beauty.

\section{Lexical features in the advertisement}

The words used are "as tested on real curves" convey confidence in the product few words, but used in passive to convey unanimity as if it had been tested by everyone. Moreover, the word 'tested' gives reliability to the product. The use of the adjective 'real' enhances the concept of reliability.

\section{To conclude}

Dove beauty aimed at provoking people to change the beauty stereotype of fashion models to the real women beauty with a wider range of skin types and body shape. The language use in this advertisement is a kind of propaganda in which Dove advertisement maker wants to influence the customers or the viewers' attitude towards an issue of changing the image of beauty stereotype. The message behind this advertisement is that Dove cares about the real women beauty by creating thought-provoking advertisement, confidence-building programs and message that embrace all definition of beauty.

\section{Similarities between the two advertisements}

- Both of them use myth to promote products.

- Both of them target dreamy women.

- Both of them make use of colors to affect audience

- Both of the advertisements are using women as a model.

- Beauty product can remove the signs of age.

- Women are the target audience.

- Both encourage luxury.

- The two advertisements are beauty products, and they refer to beauty discourse.

\section{Differences between the two advertisements}

- They use different colors, but for the same purpose.

- The second advertisement uses women sexually in an explicit way.

- The second advertisement displays six semi-naked women, while the first one focuses on the upper part of the body.

- The first advertisement uses words more effectively than the second one.

- Syntax and lexicon are used in the first one, but not clearly in the second one.

- The second one manipulates women explicitly, while the first one does not. 


\section{Conclusion}

Advertisements are a popular thing which we watch or read every day, but they are designed in a cautious way to attract customers. Advertisements can be analyzed according to different theoretical work so as to be able to understand them. The positioning of the actors of the advertisement gives a certain message, sometimes it is related to power or dominancy. The colors used also reflect another message; besides the language used which also reflects a brief and strong message. To conclude, advertisements need further studies to go deeper in understanding how they are designed to attract customers.

\section{References}

D. $(2000)$

Semiotics for beginners

(pp.

$1-244)$.

Retrieved

from

http://dominicpetrillo.com/ed/Semiotics_for_Beginners.pdf

Cook, G. (1992). The Discourse of Advertising, London.

Fairclough, N. (1989). Language and Power. London: Longman.

Gonzalez, L. M. (2005). The Impact of Ad Background Color on Brand Personality and Brand Preferences.

Jhally, S. (1987). Codes of Advertising. New York: St. Martin's Press.

Kang, M.-E. (1997). The portrayal of women's images in magazine advertisements: Goffman's gender analysis revisited. Sex Roles, 37(11-12), 979-996.

Kaur, K., Arumugam, N., \& Yunus, N. M. (2013). Beauty Product Advertisements : A Critical Discourse Analysis. Canadian Center of Science and Education, 9(3), 61-71.

Najafian, M., \& Dabaghi, A. (1991). Hidden Language of Advertising: A Semiotic Approach. arts.kmutt.ac.th, 199201.

Nicholas, P. K. M. K. (2013). Conceptualizing Beauty: A Content Analysis of U.S. and French Women's Fashion Magazine Advertisements. Journal of Communication and Media Technologies, 49-74.

Orth, U. R., \& Holancova, D. (2004). Men's and women's responses to sex role portrayals in advertisements. International Journal of Research in Marketing, 21(1), 77-88.

Sinclair, J. (1987). Images Incorporated: Advertising as Industry and Ideology. New York: Croom Helm

Tuzla, H. (2012). Does sex in print-ads affect perceived product specifications in conservative societies ?: The case of Turkey. Social and behavioral sciences, 62, 1133-1137.

Van Dijk, T. A. (1995). Discourse as Structure and Process. London: Sage. 